\title{
Mechanical vibration technique for enhancing mechanical properties of particulate reinforced aluminium alloy matrix composite
}

\begin{abstract}
The effects of subjecting solidifying particulate reinforced aluminium alloy matrix composite to various sources of vibration on the resulting casting quality, a mechanical vibration technique for inducing vibration resulting in enhanced mechanical properties, such as impact properties is devised. TiC particulate reinforced LM6 alloy matrix composites are fabricated by different particulate weight fraction of titanium dioxide and microstructure studies were conducted to determine the impact strength and density, respectively. Preliminary works show that the mechanical properties have been improved by using vibration mold during solidification compared to gravity castings without vibration.
\end{abstract}

Keyword: Composite; Impact properties; LM6; Mechanical vibration; Metal matrix composite 